\title{
Chondromodulin-1 functions as a tumor suppressor in gastric adenocarcinoma
}

\author{
PENGFEI ZHANG ${ }^{1 *}$, YING WANG $^{1 *}$, PO XU ${ }^{2 *}$, SHIYUAN SONG ${ }^{1}$, XIAOJUAN ZHU ${ }^{1}$, \\ ZHENGUO $\mathrm{SHI}^{2}$, SHEGAN GAO ${ }^{1}$ and XIAOSHAN FENG ${ }^{1}$
}

Departments of ${ }^{1}$ Oncology and ${ }^{2}$ Urology, The First Affiliated Hospital of Henan University

of Science and Technology, Luoyang, Henan 471003, P.R. China

Received April 20, 2015; Accepted May 25, 2015

DOI: 10.3892/ijo.2015.3081

\begin{abstract}
Chondromodulin-1 (ChM1) is a cartilage-specific glycoprotein that stimulates the growth of chondrocytes and inhibits the tube formation of endothelial cells. Endogenously, ChM1 is expressed in the cartilage and is an anti-angiogenic factor. ChM1 has been reported to suppress the proliferation of multiple human tumor cells in an anchorage-independent manner. However, the role of ChM1 in carcinogenesis of gastric cancer remains unknown. By quantitative RT-PCR and western blotting we examined the expression of ChM1 in gastric cancer tissue and normal gastric tissue. In vitro we investigated the functional and mechanistic roles of ChM1 in the inhibition of gastric cancer cell aggressiveness. We observed that ChM1 expression was remarkably downregulated in gastric cancer cell lines compared with the immortal normal gastric epithelial cell line GES-1. Importantly, ChM1 was frequently downregulated in gastric cancer tissue compared with normal gastric tissue. Low ChM1 mRNA expression was associated with higher clinical stages, higher lymph node metastasis, and poorer prognosis of patients. Functional assays in vitro showed that ectopic expression of ChM1 was able to inhibit gastric tumor cell proliferation by arresting the cell cycle. Overall, our findings indicate that ChM1 is a potential tumor suppressor in gastric cancer, suggesting that it may be useful as a biomarker for the treatment and prognosis of gastric cancer.
\end{abstract}

Correspondence to: Dr Shegan Gao or Dr Xiaoshan Feng, Department of Oncology, Cancer Institute, The First Affiliated Hospital of Henan University of Science and Technology, 24 Jinghua Road, Luoyang, Henan 471003, P.R. China

E-mail: gsg112258@163.com

E-mail: samfeng137@hotmail.com

${ }^{*}$ Contributed equally

Abbreviations: ChM1, chondromodulin-1; GC, gastric cancer; RLU, relative luciferase unit; STAT3, sgnal transducer and activator of transcription 3

Key words: tumor suppressor gene, chondromodulin-1, gastric cancer, carcinogenesis

\section{Introduction}

Gastric cancer is one of the leading causes of cancer-related death worldwide owing to its frequency, poor prognosis, and limited treatment options $(1,2)$. According to a study released in 2011, a total of 98,9600 new gastric cancer cases and 73,8000 deaths were estimated to have occurred in 2008, accounting for $8 \%$ of the total cases and $10 \%$ of total deaths (3). The molecular mechanisms of gastric carcinogenesis is an area of active investigation (4,5), and multiple genes have been identified, including many tumor suppressor genes that contribute to the genesis of gastric cancer in a loss-of-function manner, such as SEMA3A (6), microRNA-34b/c (7), microRNA-30b (8), and LZTFL1 (9).

Chondromodulin-1 (ChM1) is a cartilage-specific glycoprotein that stimulates the growth of chondrocytes (10) and inhibits the tube formation of endothelial cells (11). Its expression is restricted to the cartilage, and is an endogenous anti-angiogenic factor. ChM1 has been shown to suppress the proliferation of multiple human tumor cells, such as human umbilical vein endothelial cells (12), human hepatocellular carcinoma HepG2 cells (13), and human osterogenic sarcoma U-2 OS cells (14), in an anchorage-independent manner. Previous preclinical studies have demonstrated that ChM1 has anti-angiogenic and antitumor properties in vitro and in vivo that involve several complicated mechanisms $(12,15)$. In addition, ChM1 expression has been shown to be downregulated in certain pathologies, such as intervertebral disc (IVD) degeneration. Specifically, after administration of basic fibroblast growth factor (bFGF) in IVD cells, ChM1 was found to be downregulated and its expression correlated with the degree of IVD degeneration (16). However, the role of $\mathrm{ChM} 1$ in carcinogenesis of gastric cancer remains unknown.

Herein, we observed that ChM1 expression was remarkably downregulated in gastric cancer cell lines compared with the immortal normal gastric epithelial cell line, GES-1. ChM1 was frequently downregulated in gastric cancer tissue compared with normal gastric tissue. Low ChM1 mRNA expression was associated with higher clinical stages, higher lymph node metastasis, and poorer prognosis of patients. Functional assays in vitro showed that ectopic expression of ChM1 inhibited gastric tumor cell proliferation by inducing cell cycle arrest. Overall, our findings indicate that ChM1 is a potential tumor 
suppressor, which could serve as a biomarker for therapeutic and prognostic use in gastric cancer patients.

\section{Materials and methods}

Ethics statement. For tissue samples, written informed consent was obtained from patients. The procedures used in this study were approved by the Institutional Review Board of the First Military Medical University and was conformed to the Helsinki Declaration, and to local legislation.

Tissue samples. Eighty-seven pairs of snap-frozen gastric tumor and matched normal tissues from adjacent regions were provided by the Xi'jing Digestive Hospital, the Fourth Military Medical University from February 2009 to December 2011. The samples were from patients treated surgically for clinical stage I-III gastric cancer (aged 31-84 years), with informed consent from each patient. No patient received preoperative chemotherapy, radiotherapy, or hormone therapy.

RNA purification, $c D N A$ synthesis and quantitative real-time $P C R$. Total RNA of cultured cells was extracted with TRIzol reagent (Invitrogen, Carlsbad, CA, USA) according to the manufacturer's protocol and RNA was stored at $-80^{\circ} \mathrm{C}$ before qRT-PCR analysis. ChM1 expression was detected with primers: F, 5'-AGGGAAGCAAATGGAACTACTCT-3'; R, 5'-GGTGG GTCAGCAGTGTCAAA-3' (product length, $113 \mathrm{bp}$; Tm, $60^{\circ} \mathrm{C}$; GC F-43.48\%, R-55\%; start-end, 1,176-1,288 bp) and GAPDH was used as an internal control and the primers for it were: F, 5'-ACCACAGTCCATGCCATCAC-3'; R, 5'-TCCAC CACCCTGTTGCTGTA-3'. PCR products were separated on an ethidium bromide-stained $1.5 \%$ agarose gel and visualized with UV.

Cell lines and culture conditions. Gastric cancer cell lines SGC-7901, MKN-28, and the immortalized normal gastric epithelial cell line GES-1 were kindly bestowed by Professor Daiming Fan. All the cell lines were maintained in our institute according to recommended protocols. Cells were cultured in RPMI-1640 medium (Invitrogen) supplemented with $10 \%$ fetal bovine serum (FBS) (Invitrogen) at $37^{\circ} \mathrm{C}$ in a $5 \% \mathrm{CO}_{2}$ incubator.

Immunohistochemistry. Tissue paraffin sections were deparaffinized, antigen retrieval was performed using citrate sodium buffer ( $\mathrm{pH} \mathrm{7.2)}$ at $95^{\circ} \mathrm{C}$ for $15 \mathrm{~min}$, and the endogenous peroxidase was blocked using $3 \%$ hydrogen peroxide for $15 \mathrm{~min}$. Then, the sections were treated with normal goat serum for $30 \mathrm{~min}$ to reduce non-specific binding followed by rabbit polyclonal anti-ChM1 (1:200, SC-33563, Santa Cruz Biotechnology, Inc., Santa Cruz, CA, USA) incubating for $1 \mathrm{~h}$ at $37^{\circ} \mathrm{C}$. Finally, sections were incubated with secondary antibody for $30 \mathrm{~min}$ at room temperature. Diaminobenzidine was used for color reactions (17).

DNA synthesis assay (BrdU incorporation). To assess the proliferation of cells, BrdU incorporation assay was used. Cells were harvested with trypsin/EDTA and suspended in RPMI-1640, as appropriate. The cells were seeded at $2 \times 10^{4}$ cells $/ \mathrm{ml}$ into a 96 -well multi-titer plate (100 $\mu \mathrm{l} /$ well $)$ and cultured for $24 \mathrm{~h}$. The cells were then starved in $0.5 \% \mathrm{FBS}$ containing Opti-MEM for $12 \mathrm{~h}$ and stimulated with $10 \mathrm{ng} / \mathrm{ml}$ fibroblast growth factor-2 (FGF-2) (Yope Biotech Co., Ltd., Shanghai, China) in either the presence or absence of $25 \mu \mathrm{g} / \mathrm{ml}$ recombinant human ChM1 (rhChM1) for another $24 \mathrm{~h}$. Cells were labeled with BrdU during the last $3 \mathrm{~h}$ of this incubation. The medium was then replaced with one containing either 10 or $25 \mu \mathrm{g} / \mathrm{ml} \mathrm{rhChM} 1$, BrdU was added, and the cells were cultured for 6,12 or $24 \mathrm{~h}$. BrdU incorporation by the cells was measured at least in triplicate at each time-point using a cell proliferation ELISA BrdU colorimetric kit according to the manufacturer's instructions (Laizee Biotech Co., Ltd., Shanghai, China). The BrdU colorimetric kit was read for absorbance at $450 \mathrm{~nm}$, and referenced at $655 \mathrm{~nm}$, using a Model 680 Microplate Reader (Bio-Rad, Hercules, CA, USA).

Small interference RNA (siRNA) transfection. To knock down the ChM1 mRNA expression, siRNA transfection was performed. For transfections, Lipofectamine 2000 (Invitrogen) and $100 \mathrm{nM}$ siRNA (Gene Pharma Co., Shanghai, China) were used according to the manufacturer's recommendations as described previously (18). Seventy-two hours after transfection, cells were used for examination, western blotting, and CCK-8 assay. The silenced cell line was named as SGC7901siChM1 or MKN28-siChM1, while the matched control cell lines were named as SGC7901-siCtrl or MKN28-siCtrl, respectively. The siRNA sequences used are: 5'-UGGAUUUA UCCUACAGAUGCA-3'; 5'-CAUCUGUAGGAUAAAUCC AUA-3'.

Construction of pcDNA3.1(+)-ChM1 plasmid. To overexpress ChM1, pcDNA3.1(+)-ChM1 plasmid was constructed. The human ChM1 cDNA expression vector (pcDNA3.1(+)-ChM1) was constructed by $\mathrm{CW}$ Biotech Co., Ltd., Beijing, China. Briefly, the plasmid pcDNA3.1(+)-ChM1 was generated according to the cDNA sequence from GenBank. The ChM1 gene was generated by PCR amplification. The plasmid pcDNA3.1(+) was extracted through a Maxi Preparation kit (Omega, GA, USA). The PCR product was subcloned into the BamHI (Takara, Mountain View, CA, USA) and HindIII (Takara) sites of pcDNA3.1 plasmid by T4 ligase (Takara). The pcDNA3.1(+)-ChM1 construct was verified by DNA sequencing (Invitrogen, Grand Island, NY, USA) (data not shown).

Generation of ChM1 stable cell lines. To empirically determine the proper concentration of G418 antibiotic to use for selection of ChM1 stable-expressing clones, SGC-7901, MKN-28 cells were cultured in 12 -well plates with $1.0 \times 10^{5}$ cells in each well, in an incubator with constant supply of $5 \% \mathrm{CO}_{2}$ at $37^{\circ} \mathrm{C}$. The medium was changed $24 \mathrm{~h}$ later with different concentrations of antibiotic G418 (0, 50, 100, 200, 400, 600, 800 and $1,000 \mu \mathrm{g} / \mathrm{ml}$ ) and replaced every 3 days. Medium with $800 \mu \mathrm{g} / \mathrm{ml} \mathrm{G} 418$ was used for further experiments as it is the minimum concentration to induce total cell death 14 days after cell culture. Having determined the proper G418 concentration for selection, parental cells were transfected with the pcDNA3.1(+)-ChM1 plasmids using Lipofectamine 2000 according to the manufacturer's instructions. The density of cells was $2 \times 10^{5}$ cells per well in 6 -well plates. Monoclonal cell 
colony with G418 resistance was generated using the limiting dilution method by culturing single cell in $100 \mu 1$ medium in 96-well plates for $24 \mathrm{~h}$. Monoclonal cell colonies were digested 15 days later for further amplification to culture cells with stable ChM1 expression in 24-well plates. Cells were transferred to cell culture flask until $\sim 90 \%$ confluent. The ChM1 overexpressed cell lines transfected by pcDNA3.1(+)-ChM1 were named as SGC7901-ChM1 or MKN28-ChM1, while the matched control cell lines were named as SGC7901-NC or MKN28-NC, respectively.

Cell counting kit (CCK-8) assay. Cell viability was performed using the Cell Counting kit (CCK-8; Dojindo Laboratories, Kumamoto, Japan) assay, as described previously (19). Cells were seeded in $200 \mu \mathrm{l} /$ well of medium at a concentration of $1 \times 10^{4}$ cells/well into 96 -well plates and incubated overnight for attachment. Then, culture medium was removed and fresh medium (100 $\mu \mathrm{l} /$ well) and $10 \mu \mathrm{l}$ CCK-8 solution were added and cells were incubated for $1 \mathrm{~h}$ at $37^{\circ} \mathrm{C}$. The optical density (OD) value (absorbance) was measured at $450 \mathrm{~nm}$ by a microplate spectrophotometer (Multiskan, MK3, Thermo, USA). All experiments were performed in quadruple on three separate occasions.

Colony-formation assay. To assess the anchorage-dependent proliferation of cells, a colony-formation assay was performed. The log-phase cells were harvested, plated into 6-well plates (500 cells/well), and chemotherapeutic drugs were added into the culture medium on the second day. The resulting colonies were stained with Coomassie Brilliant Blue (Sigma, Inc., St. Louis, MO, USA), and the visible colonies were counted after 2 weeks.

Cell invasion and migration assays. Cell invasion and migration capacity was assessed by Transwell permeable supports with $8-\mu \mathrm{m}$ pore size (Costar, Cambridge, MA, USA). As instructed by the manufacturer, cells suspended in serum-free medium were seeded into Transwell inserts either uncoated (for migration assay) or coated (for invasion assay) with growth factor-reduced Matrigel (BD Biosciences, Bedford, MA, USA) (20). Bottom wells were incubated with complete medium, and $24 \mathrm{~h}$ later the invaded cells were fixed with methanol and stained with a crystal violet solution. The number of cells that penetrated the membrane was determined by counting the mean cell number in five randomly selected high-power fields.

Western blotting. Total protein from cultured cells were lysed using lysis buffer supplemented with phenylmethylsulfonyl fluoride $(1 \mathrm{mM})$ on ice. Protein was electrophoresed through $12 \%$ SDS polyacrylamide gels and then transferred to a PVDF membrane (Millipore, MA, USA). Membranes were blocked with $5 \%$ non-fat milk powder at room temperature for $1 \mathrm{~h}$ and incubated overnight with primary antibodies. Membranes were incubated with secondary antibodies labeled with HRP for $1 \mathrm{~h}$ at room temperature after three 10-min washes in triethanolamine buffered saline solution with Tween (TBS-T). Finally, the signals were detected using an ECL kit (Pierce Biotech., Rockford, IL, USA) and the membranes were scanned and analyzed using a ChemiDoc XRS+ (Bio-Rad, CA, USA) imaging system with imaging software (Version 1.0). The protein expression was normalized to an endogenous reference GAPDH and relative to the control. The Spectra multicolor broad-range protein ladder (Beyotime, Jiangsu, China) was used as a molecular marker. The antibodies used in the western blot assay are as follows: ChM1, sc-33563, 1:200, 25 kDa; Akt, sc-1618, 1:200, 62 kDa; GSK-3ß, sc-377213, 1:100, 47 kDa; GAPDH, sc-365062, 1:5,000, 37 kDa (Santa Cruz Biotechnology, Inc. TX, USA)

Luciferase reporter assay. The nucleotide sequence of the STAT response elements was 5'-gatccagttcccgtcaatcg-3'. These constructs express Renilla luciferase. A reference construct was prepared by digesting the HSV-TK promoter between the BamH1 site and HindIII sites from the pRL-TK vector (Promega Corp., Madison, WI, USA) that expresses Renilla luciferase, and cloning this fragment into the pGL4.18 [luc $2 \mathrm{p} / \mathrm{Neo}$ ] vector (Promega) that expresses Firefly luciferase. The cells were infected with virus and cultured for $12 \mathrm{~h}$ then washed twice with culture medium and then transfected with various luciferase expression vectors by the lipofection method. The cells were harvested $24 \mathrm{~h}$ after transfection, and a Dual-Luciferase ${ }^{\mathrm{TM}}$ reporter assay system (Promega) was performed for sequential measurement of Firefly and Renilla luciferase activities using the specific substrates beetle luciferin and coelenterazine, respectively. Quantification of luciferase activities and calculation of relative ratios were carried out using a luminometer (TD-20/20, Turner Designs, Sunnyvale, CA, USA). In these experiments, at least three independent transfections were performed.

Statistical analysis. The data were analyzed using SPSS 12.0 software (SPSS Inc., Chicago, IL, USA). All experiments in this study were repeated in triplicate. The Student's t-test was used to analyze the statistical significance of the differences between groups. $\chi^{2}$ test and Fisher's exact test were used to assess the correlation between ChM1 and clinical pathologic parameters. For all the tests, P-values $<0.05$ was considered statistically significant.

\section{Results}

ChM1 was downregulated in human gastric cancer cells. ChM1 expression in four gastric cancer cell lines and one immortal normal gastric epithelial cell line were quantified by qRT-PCR (Fig. 1A) and western blotting (Fig. 1B). Among the five cell lines analyzed, ChM1 was found to be expressed at lower levels in gastric cancer cells, compared with normal mammary gastric epithelial GES-1 cells. Among the gastric cancer cells, SGC7901, MKN28, and GC9811 cells expressed relatively higher levels of ChM1, compared with the BGC-823 cell line, which had low expression or barely detectable ChM1 levels.

Expression of ChM1 is downregulated in human gastric cancer tissue. We found that ChM1 was significantly downregulated in $61(70 \%)$ gastric cancer clinical tissues, compared with non-cancerous tissues (Fig. 2A). ChM1 expression of human gastric cancer clinical tissues was examined by immunohistochemistry and western blotting, which indicated that 59 and 63 patients had significantly lower ChM1 expression, 
A

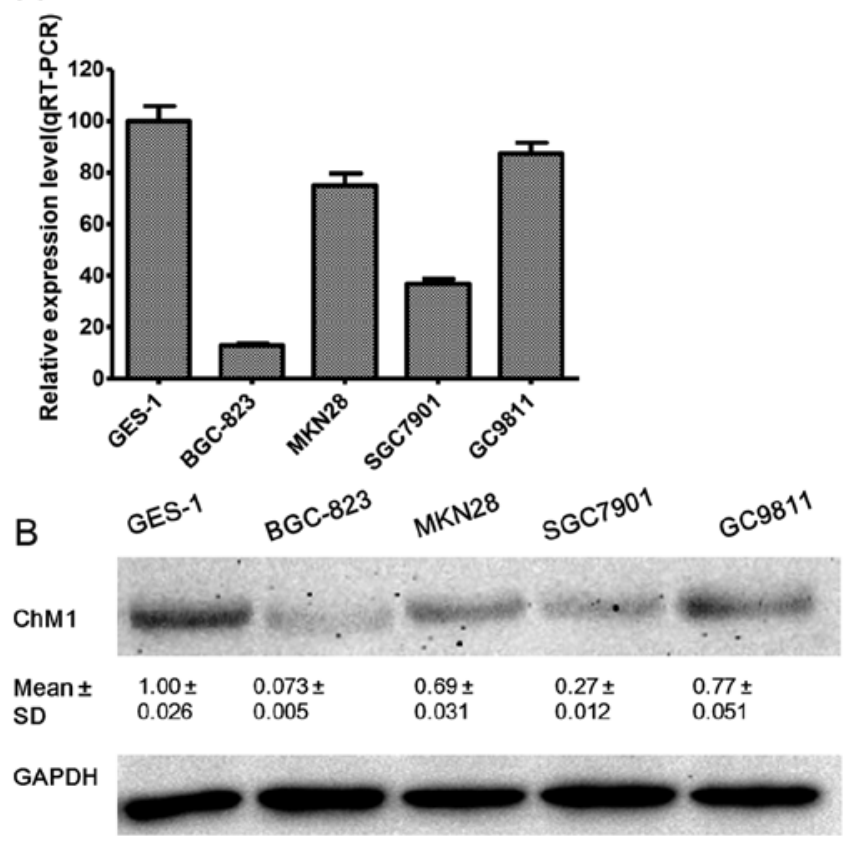

Figure 1. ChM1 expression in gastric cell lines. (A) ChM1 expression in four gastric cancer cell lines and GES-1 were quantified by qRT-PCR (one-way ANOVA analysis, $\mathrm{F}=689.4,{ }^{* * * *} \mathrm{P}<0.0001$ ). (B) $\mathrm{ChM} 1$ expression in four gastric cancer cell lines and GES-1 were quantified by western blotting (one-way ANOVA analysis, $\left.\mathrm{F}=146.6,{ }^{* * * *} \mathrm{P}<0.0001\right)$. Data were means of three separate experiments (mean $\pm \mathrm{SD}$ ).

as detected by immunohistochemistry (Fig. 2B) and western blotting (Fig. 2C) analysis, respectively. To gain further insight into this observation, we examined the relationship between ChM1 expression and the patients' clinical parameters. Analysis showed that ChM1 expression negatively correlated with lymph node metastasis and tumor-node-metastasis (TNM) stage (Tables I and II), but was irrelevant with age, sex, tumor differentiation, and tumor size.

ChM1 inhibits proliferation and growth in human gastric cancer cells in vitro. To investigate the role of ChM1 in the proliferation and growth of human gastric cancer cells, we generated gastric cancer cell lines to overexpress ChM1. Cells were transfected with pcDNA3.1(+)-ChM1, and after antibiotic selection the stable clones were named as SGC7901-ChM1 or MKN28-ChM1, while the matched control cell lines were named as SGC7901-NC or MKN28-NC, respectively. In addition, we also knocked down ChM1 using siRNA. The silenced cell line was named as SGC7901-siChM1 or MKN28-siChM1, while the matched control cell lines were named as SGC7901-siCtrl or MKN28-siCtrl, respectively. The expression levels were determined using both western blot (Fig. 3A and B) and qRT-PCR (Fig. 3C and D) analyses. As shown in Fig. 3E and F, ChM1 overexpression led to a significant decrease in cell proliferation, while ChM1 knockdown led to a significant increase in cell proliferation. To further demonstrate the mechanism by which ChM1 overexpression or knockdown affected proliferation, cell cycle progression was analyzed using flow cytometry. SGC7901-ChM1 cells showed a delayed G1 phase compared with SGC7901-NC cells, while MKN28-ChM1 cells also showed a delayed G1 phase
Table I. The relationship between clinical parameters and ChM1 $($ mean $\pm \mathrm{SD}) \mathrm{mRNA}$ expression in primary gastric adenocarcinoma.

\begin{tabular}{lccl}
\hline $\begin{array}{l}\text { Clinical } \\
\text { parameters }\end{array}$ & $\mathrm{N}(\%)$ & $\begin{array}{c}\text { Relative } \\
\text { expression }\end{array}$ & P-value \\
\hline $\begin{array}{l}\text { Age (years) } \\
\geq 60\end{array}$ & $38(43.7)$ & $0.4317 \pm 0.02569$ & 0.44 \\
$<60$ & $49(56.3)$ & $0.4168 \pm 0.01972$ & \\
Gender & & & \\
$\quad$ Male & $64(73.6)$ & $0.4095 \pm 0.01903$ & 0.59 \\
Female & $23(26.4)$ & $0.4257 \pm 0.01655$ & \\
Size (cm) & & & \\
$\geq 5$ & $52(59.8)$ & $0.3921 \pm 0.02215$ & 0.31 \\
$<5$ & $35(40.2)$ & $0.4292 \pm 0.02734$ & \\
$\begin{array}{l}\text { Histologic } \\
\text { differentiation }\end{array}$ & & & \\
Well (W) & $26(29.9)$ & $0.4325 \pm 0.01833$ & 0.37 \\
Moderately (M) & $32(41.4)$ & $0.4196 \pm 0.02360$ & \\
Poorly (P) & $29(28.7)$ & $0.4078 \pm 0.02074$ & \\
Lymphatic & & & \\
metastasis & & & \\
No & $29(29.9)$ & $0.5702 \pm 0.05269$ & $0.0017^{\mathrm{a}}$ \\
Yes & $58(70.1)$ & $0.3615 \pm 0.02173$ & \\
$\begin{array}{l}\text { TNM stage } \\
\text { Stage I }\end{array}$ & $22(25.3)$ & $0.5481 \pm 0.04722$ & $0.0025^{\mathrm{a}}$ \\
Stage II/III & $65(74.7)$ & $0.3969 \pm 0.03341$ & \\
\hline & & & \\
\hline
\end{tabular}

Table II. The relationship between clinical parameters and $\mathrm{ChM} 1$ protein expression in primary gastric adenocarcinoma.

\begin{tabular}{|c|c|c|c|c|}
\hline $\begin{array}{l}\text { Clinical } \\
\text { parameters }\end{array}$ & $\mathrm{N}(\%)$ & $\begin{array}{l}\text { ChM1 low } \\
\text { expression }\end{array}$ & $\begin{array}{l}\text { ChM1 high } \\
\text { expression }\end{array}$ & P-value \\
\hline \multicolumn{5}{|l|}{ Age (years) } \\
\hline$\geq 60$ & $38(43.7)$ & 27 & 11 & \multirow[t]{2}{*}{0.82} \\
\hline$<60$ & $49(56.3)$ & 36 & 13 & \\
\hline \multicolumn{5}{|l|}{ Gender } \\
\hline Male & 64 (73.6) & 47 & 17 & \multirow[t]{2}{*}{1.00} \\
\hline Female & $23(26.4)$ & 17 & 6 & \\
\hline \multicolumn{5}{|l|}{ Size $(\mathrm{cm})$} \\
\hline$\geq 5$ & $52(59.8)$ & 39 & 13 & \multirow[t]{2}{*}{0.62} \\
\hline$<5$ & $35(40.2)$ & 24 & 11 & \\
\hline \multicolumn{5}{|l|}{$\begin{array}{l}\text { Histologic } \\
\text { differentiation }\end{array}$} \\
\hline Well & $26(29.9)$ & 18 & 8 & \multirow[t]{3}{*}{0.99} \\
\hline Moderately & $32(41.4)$ & 22 & 10 & \\
\hline Poorly & $29(28.7)$ & 20 & 9 & \\
\hline \multicolumn{5}{|l|}{$\begin{array}{l}\text { Lymph node/ } \\
\text { venous } \\
\text { metastasis }\end{array}$} \\
\hline No & $21(24.1)$ & 7 & 14 & \multirow[t]{2}{*}{$<0.01^{\mathrm{a}}$} \\
\hline Yes & $66(75.9)$ & 49 & 17 & \\
\hline \multicolumn{5}{|l|}{ TNM stage } \\
\hline Stage I & $22(25.3)$ & 9 & 13 & \multirow[t]{3}{*}{$0.016^{\mathrm{a}}$} \\
\hline Stage II & $30(34.5)$ & 21 & 9 & \\
\hline Stage III & $35(40.2)$ & 29 & 6 & \\
\hline
\end{tabular}



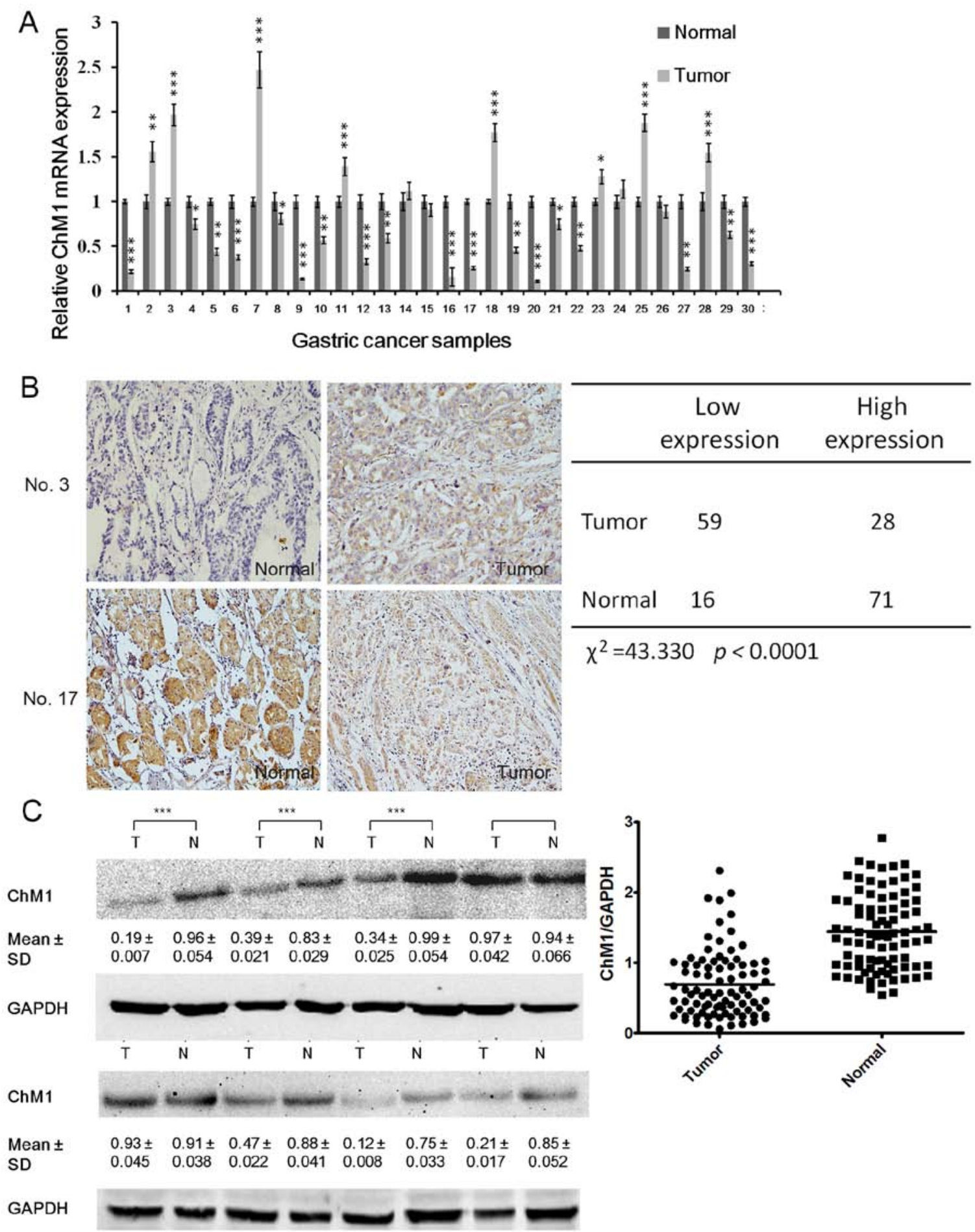

Figure 2. ChM1 expression in gastric cancer tissue. (A-C) ChM1 expression in gastric cancer tissues examined by qRT-PCR (A), immunohistochemistry (B) and western blotting (the gray value ratio of GES-1 cell line was taken as 1.00) (C). Data were means of three separate experiments (mean \pm SD), one-way ANOVA analysis, ${ }^{* * *} \mathrm{P}<0.0001,{ }^{* *} \mathrm{P}<0.001,{ }^{*} \mathrm{P}<0.05$.

compared with MKN28-NC cells (Fig. 3G). The ability of SGC7901 or MKN28 cells to form colonies was inhibited when ChM1 was overexpressed. Conversely, the ability of SGC7901 or MKN28 cells to form colonies was enhanced when ChM1 was knocked down (Fig. 3H).

ChM1 suppresses migratory and invasive potential. In addition to regulating cell proliferation, ChM1 was also found to regulate SGC7901 cell migration and invasion. As shown in Fig. 4A and C, the overexpression of ChM1 decreased cell migration in a gap wound assay after $24 \mathrm{~h}$ by $45 \mu \mathrm{m}$ (Fig. 4A), while ChM1 knockdown increased migration by $89 \mu \mathrm{m}$ (Fig. 4C), compared with the control cells. In addition, a three-dimensional cell migration assay was performed using transwell chambers and an invasion assay was performed with Matrigel-precoated transwell chambers. It was found that ChM1 overexpression exhibited a significant reduction in the migration and invasion capabilities (Fig. 4B). Conversely, 
A

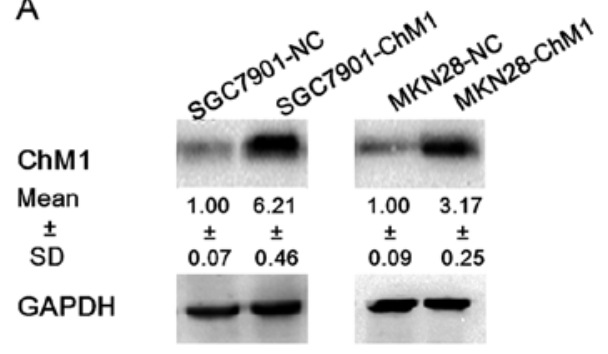

B

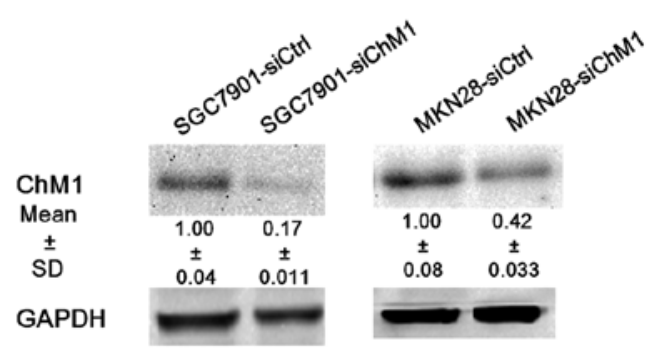

C

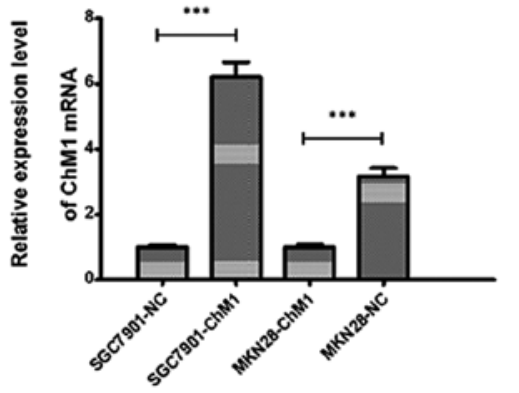

E

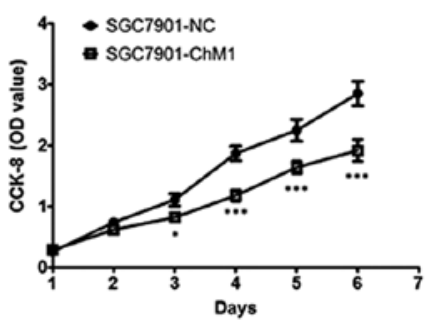

$\mathrm{F}$

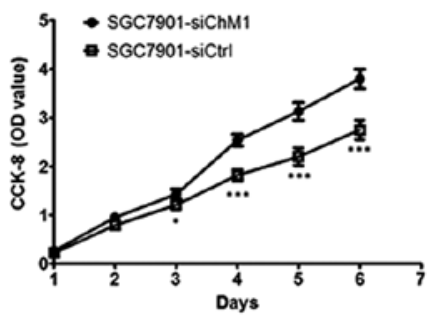

G

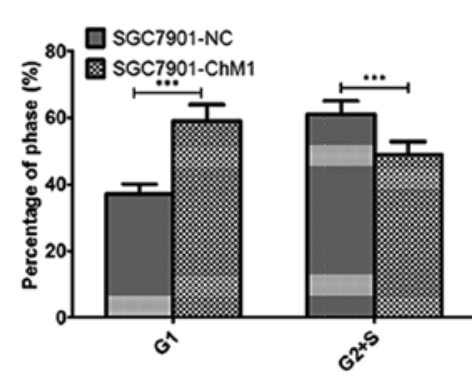

$\mathrm{H}$

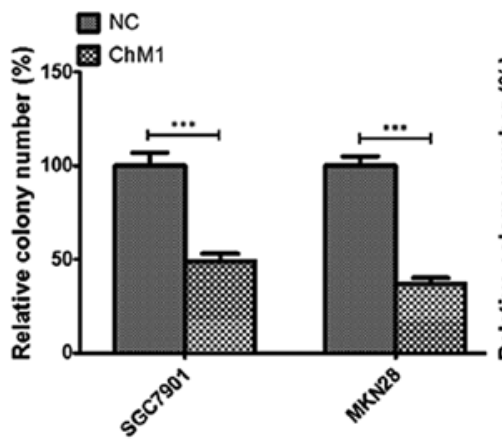

D
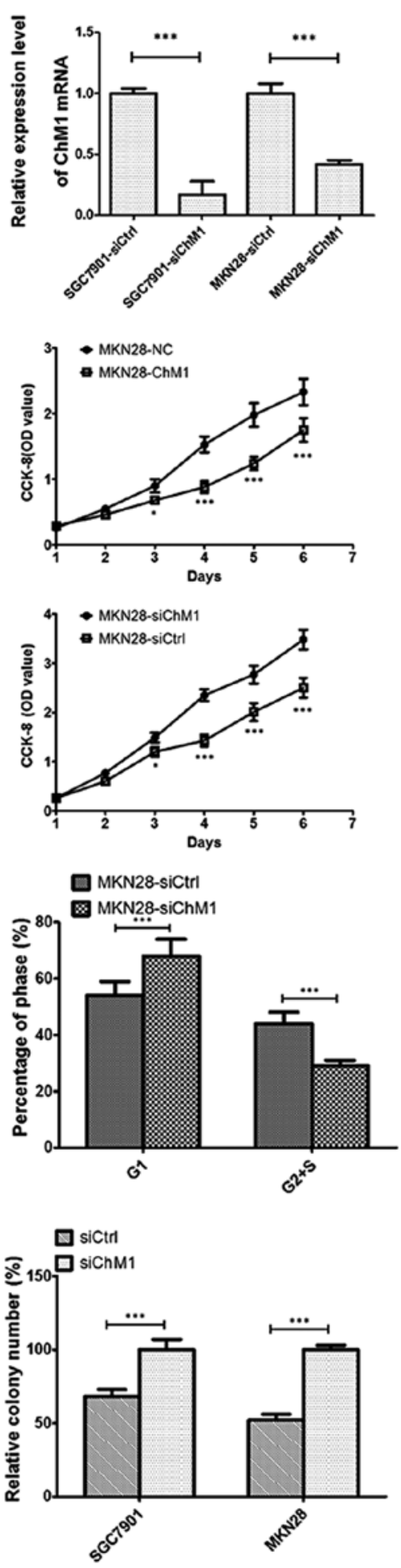

Figure 3. Effect of ChM1 on proliferation and growth of gastric cancer cell lines SGC7901 and MKN28. (A and B) Western blotting and (C and D) qRT-PCR methods were used to examine ChM1 expression. (E and F) The growth of cells over 6 days was examined using cell counting kit (CCK-8) assays. (G) Percentage of phase of cell cycle progression measured by flow cytometry. (H) Colony number of SGC7901 and MKN28 cells in soft agar. Data were means of three separate experiments (mean $\pm \mathrm{SD}),{ }^{*} \mathrm{P}<0.05,{ }^{* *} \mathrm{P}<0.001,{ }^{* * *} \mathrm{P}<0.0001$. 
A
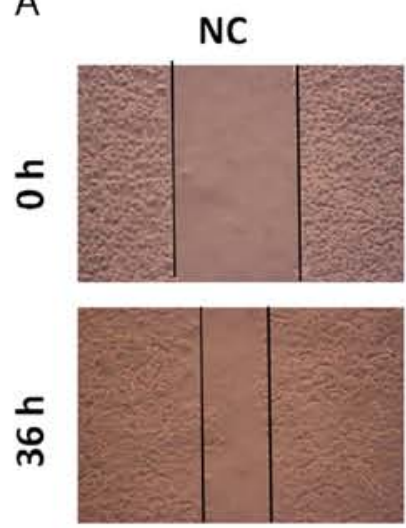

B
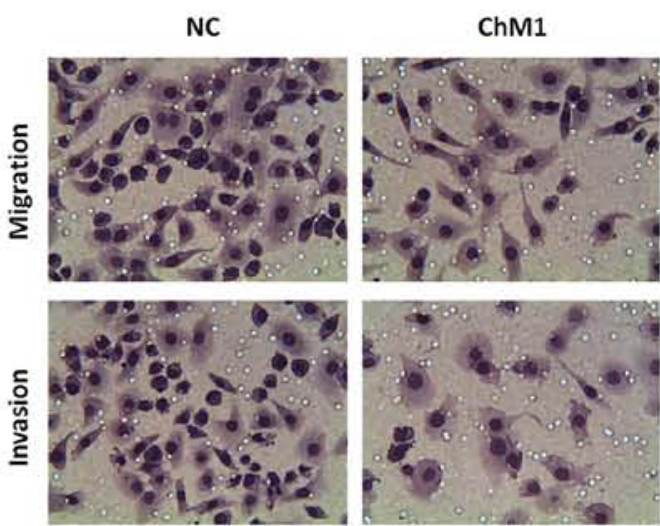
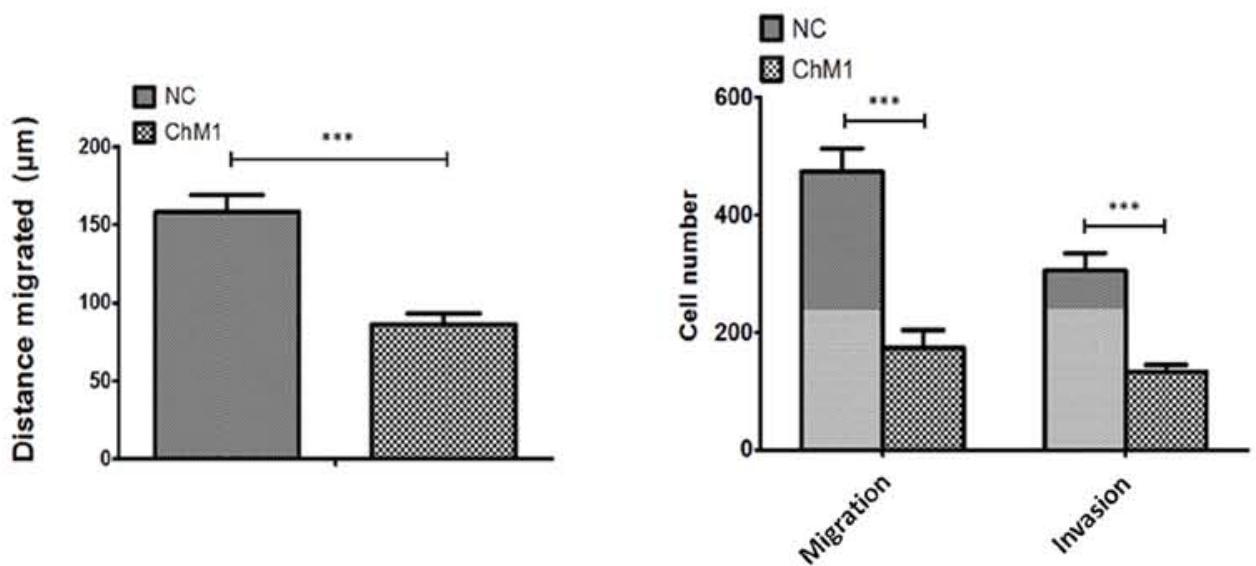

C

D
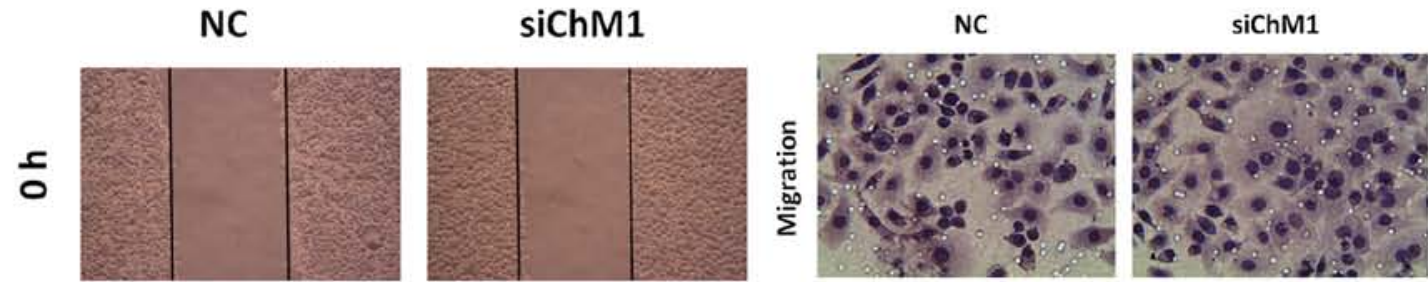

siChM1
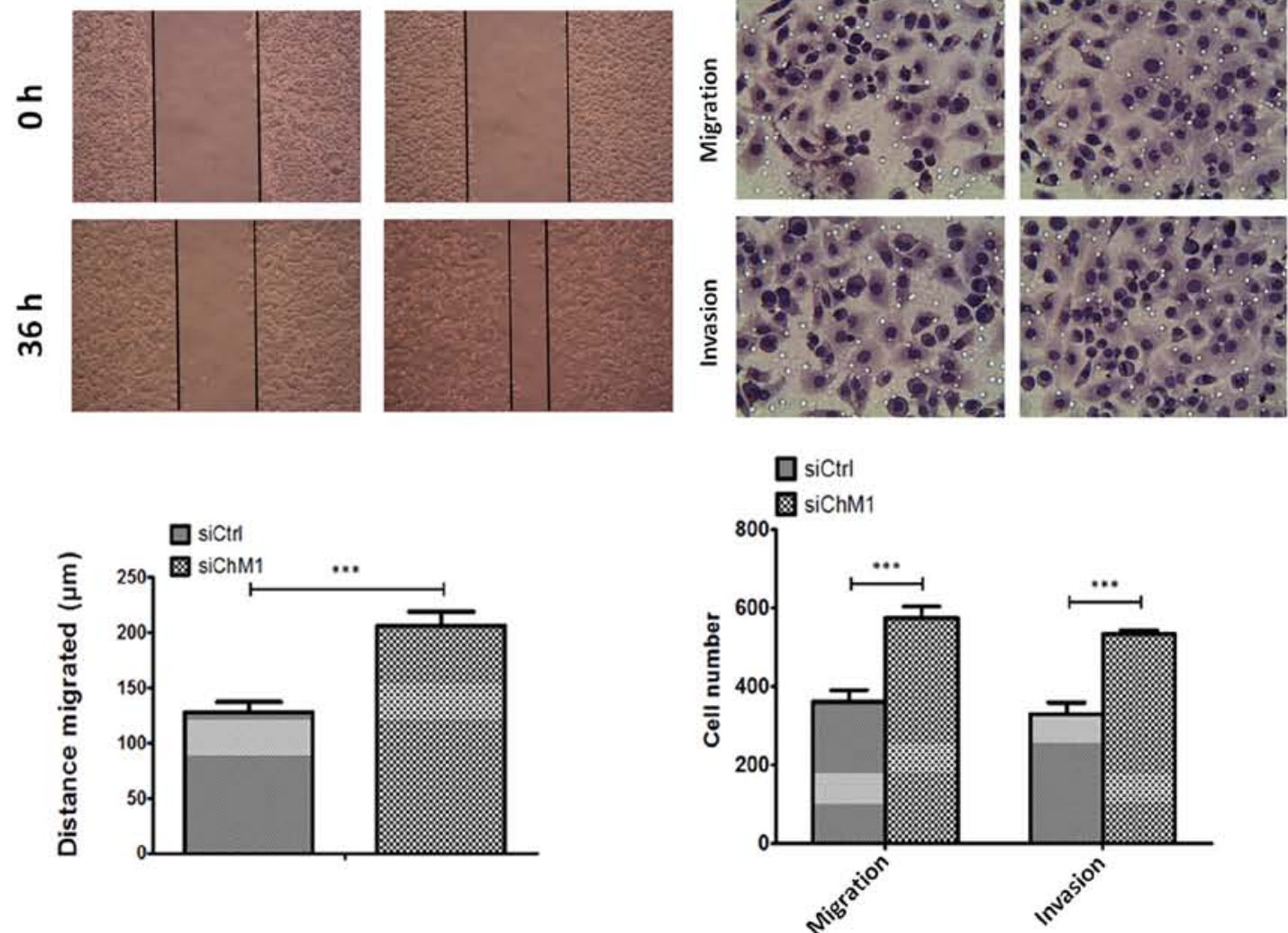

Figure 4. ChM1 significantly suppressed migratory and invasive potential of the gastric cancer cell line SGC7901. (A and C) Wound healing assay. Images of wound repair were taken at 0 and $36 \mathrm{~h}$ after wounding. The distance of wound closure is shown by area at $36 \mathrm{~h}$. Representative images (upper) and quantification (lower) are shown, original magnification, x200. (B and D) Transwell migration assay and Matrigel invasion assay. Representative images (upper) and quantification (lower) are shown. Columns, average of three independent experiments, ${ }^{* * *} \mathrm{P}<0.0001$, original magnification, $\mathrm{x} 200$. 
A

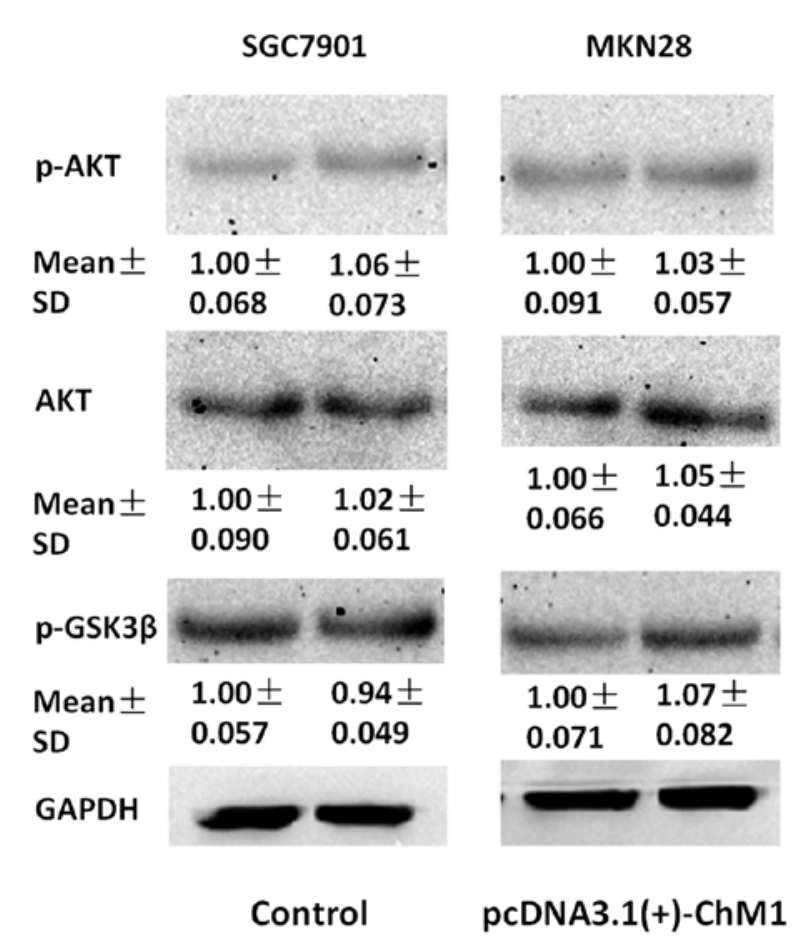

B
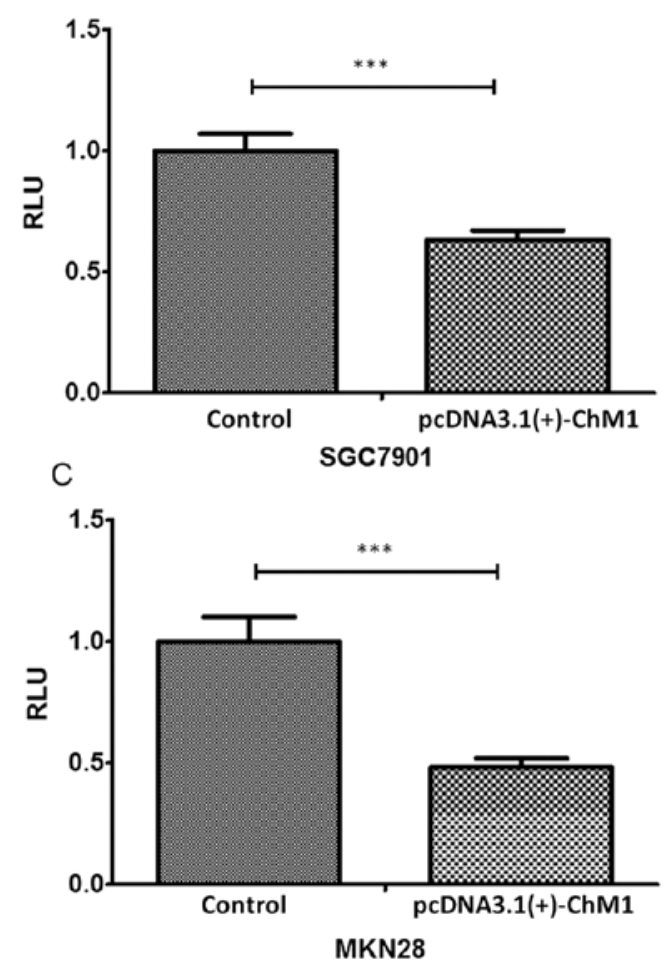

Figure 5. The effect of ChM1 on the downstream pathway of extracellular matrix-integrin signaling and STAT pathway. Western blotting (A) showing phosphorylation levels of Akt and GSK3 $\beta$, the downstream molecules of the extracellular matrix-integrin signaling pathway. (B and C) pcDNA3.1(+)-ChM1 inhibited the promoter activity of STAT-luc in SGC7901 and MKN28. ${ }^{* * *} \mathrm{P}<0.0001$.

A

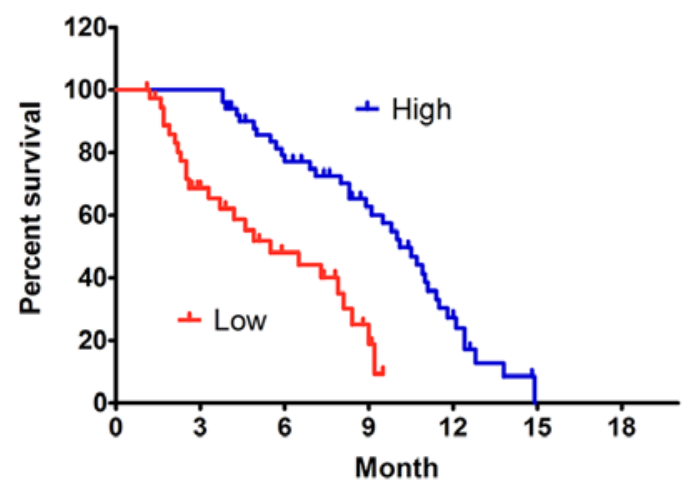

B

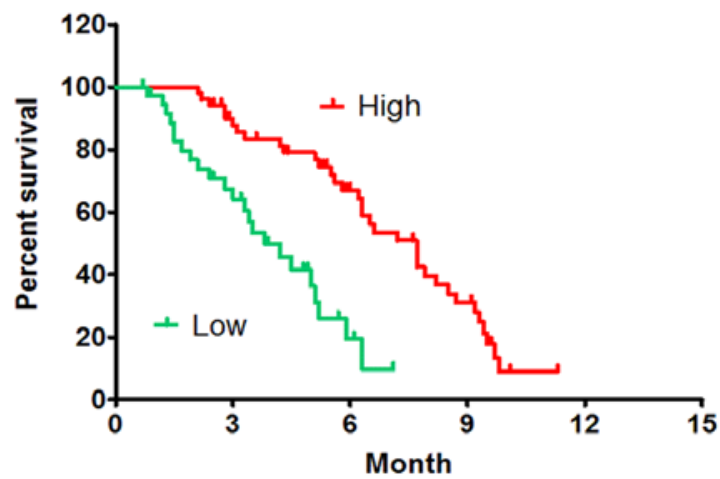

Figure 6. Low ChM1 expression correlates with poor survival in gastric cancer. Kaplan-Meier survival curves of overall (A) and event-free (B) survival. Low ChM1 expression correlates with favorable overall $(\mathrm{P}<0.0001)$ and event-free $(\mathrm{P}<0.0001)$ survival, whereas low ChM1 expression correlates with poor outcome. Cut-point analysis for overall and event-free survival was done for ChM1 using maximally selected rank statistics. The optimal cut-point was relative expression level at 0.56 for overall survival as well as event-free survival. Relative expression level above this cut-point were considered as high ChM1 expression, whereas lower values were considered as low ChM1 expression.

ChM1 knockdown exhibited a significant increase in migration and invasion capabilities (Fig. 4D).

Effect of ChM1 on downstream molecules of the extracellular matrix-integrin signaling and STAT pathways. Given that ChM1 has a direct antitumor effect by inhibiting the STAT signaling pathway, we verified this pathway to establish the potential pathway via which ChM1 exerted its tumor suppressor role (21). The results from our soft- agar assay demonstrated that ChM1 directly suppressed anchorage-independent tumor cell growth. Therefore, to further illustrate the mechanism of this function, the anchorage-dependent signaling including integrins and their downstream signaling pathway, which includes Akt and glycogen synthase kinase 3- $\beta$ (GSK3 $\beta$ ) (22-24) were examined. It was found that phosphorylation of Akt and GSK3 $\beta$ was unaffected $24 \mathrm{~h}$ post-pcDNA3.1(+)-ChM1 transfection (Fig. 5A). Furthermore, the luciferase reporter assay showed 
that pcDNA3.1(+)-ChM1 inhibited the promoter activity of STAT-luc in SGC7901 and MKN28 cultured on plates (Fig. 5B and C).

Low ChM1 expression levels indicates poorer clinical outcome of GC patients. Low ChM1 transcript level indicates poorer clinical outcome of GC patients. In this study, Kaplan-Meier estimates for overall survival and event-free survival were calculated to determine whether ChM1 expression levels are related to differences in clinical outcome. It showed that ChM1 expression was negatively correlated with patients outcome. In GCs with low ChM1 expression, median survival time was 5.5 months versus 10.1 months in tumors with high ChM1 expression (ratio $=1.836$, 95\% confidence interval of ratio, 1.240-2.433) (Fig. 6A). Event-free survival was 3.8 months versus 7.7 months (ratio $=2.026$, 95\% confidence interval of ratio, 1.437-2.615), respectively (Fig. 6B).

\section{Discussion}

In this study, we discovered three lines of evidence supporting a critical role for ChM1 in gastric cancer progression. First, we found that ChM1 expression was downregulated in gastric cancer, which was significantly associated with both lymph node metastasis and TNM stage of gastric cancer patients. Second, exogenous expression of ChM1 led to decreased cell growth and invasive properties in vitro, whereas knockdown of ChM1 resulted in greater cell growth and invasiveness. Third, ChM1 suppressed the expression of STAT. Therefore, we propose a new role for ChM1 as a novel suppressor of tumor invasion and metastasis in gastric cancer.

Invasion and metastasis have been shown to be important hallmarks of cancer. It has been found that local administration of recombinant human ChM1 almost completely blocked vascular invasion and tumor growth in vivo. Moreover, ChM1 also inhibited the growth of HT-29 colon adenocarcinoma cells in vivo, implying its therapeutic potential for solid tumors (25). Our study showed that ChM1 expression decreased the invasive potential and suppressed the metastasis potential of gastric cancer cells, suggesting ChM1 might serve as a suppressor of metastasis.

A previous study demonstrated that ChM1 knockout directly interfered with in vivo ectopic cartilage regeneration when chondrocytes were subcutaneously injected into nude mice with Matrigel $(26,27)$. Moreover, ChM1 knockout compromised ectopic stability of in vitro regenerated cartilage after subcutaneous implantation (28). Furthermore, ChM1 removal from the inner meniscus-derived medium and functional blocking of ChM1 significantly increased endothelial cell proliferation, suggesting that ChM1 may be a key anti-angiogenic factor for maintaining the avascularity of the inner meniscus (29-31). Intriguingly, we found that ChM1 had a greater effect on gastric cancer cell invasion than cell growth, which prompted us to focus our studies on the role of ChM1 in gastric cancer invasion.

Signal transducer and activator of transcription 3 (STAT3) exerts an essential role in a variety of physiological functions, including development $(32,33)$, proliferation $(34,35)$, and immune defense (36). Increasing evidence indicates that STAT3 promotes tumorigenesis of a variety of cancers
$(37,38)$, causing it to be recognized as an oncogene $(39,40)$. In fact, strategies aimed at the co-targeting of STAT3/NF- $\kappa B$ activation and the interaction between them has garnered attention in other cancers, such as colorectal cancer, and might be an attractive and novel approach to combat gastric cancer (41).

In general, we have found that ChM1 acts as a tumor suppressor by inhibiting the growth of gastric cancer cells, and the mechanism of the induced growth arrest appears to involve the anchorage-independent Jak/STAT pathway.

\section{Acknowledgements}

This study was supported by National Natural Science Foundation of China (no. 81301763) and the Henan Provincial Key Scientific and Technological Projects (no. 142102310473).

\section{References}

1. Compare D, Rocco A and Nardone G: Risk factors in gastric cancer. Eur Rev Med Pharmacol Sci 14: 302-308, 2010.

2. Brenner H, Rothenbacher D and Arndt V: Epidemiology of stomach cancer. In: Cancer Epidemiology. Springer, pp467-477, 2009.

3. Jemal A, Bray F, Center MM, Ferlay J, Ward E and Forman D: Global cancer statistics. CA Cancer J Clin 61: 69-90, 2011.

4. Wu WK, Cho CH, Lee CW, Fan D, Wu K, Yu J and Sung JJ: Dysregulation of cellular signaling in gastric cancer. Cancer Lett 295: 144-153, 2010.

5. Fan D, Zhang X, Chen X, Mou Z, Hu J, Zhou S, Ding J and Wu K: Bird's-eye view on gastric cancer research of the past 25 years. J Gastroenterol Hepatol 20: 360-365, 2005.

6. Kuzuhara T, Suganuma M, Kurusu M and Fujiki H: Helicobacter pylori-secreting protein Tip $\alpha$ is a potent inducer of chemokine gene expressions in stomach cancer cells. J Cancer Res Clin Oncol 133: 287-296, 2007.

7. Suzuki H, Yamamoto E, Nojima M, Kai M, Yamano HO, Yoshikawa K, Kimura T, Kudo T, Harada E, Sugai T, et al: Methylation-associated silencing of microRNA-34b/c in gastric cancer and its involvement in an epigenetic field defect. Carcinogenesis 31: 2066-2073, 2010.

8. Qiao F, Zhang K, Gong P, Wang L, Hu J, Lu S and Fan H: Decreased miR-30b-5p expression by DNMT1 methylation regulation involved in gastric cancer metastasis. Mol Biol Rep 41: 5693-5700, 2014.

9. Wei Q, Zhou W, Wang W, Gao B, Wang L, Cao J and Liu ZP: Tumor-suppressive functions of leucine zipper transcription factor-like 1. Cancer Res 70: 2942-2950, 2010.

10. Yanagihara I, Yamagata M, Sakai N, Shukunami C, Kurahashi H, Yamazaki M, Michigami T, Hiraki Y and Ozono K: Genomic organization of the human chondromodulin-1 gene containing a promoter region that confers the expression of reporter gene in chondrogenic ATDC5 cells. J Bone Miner Res 15: 421-429, 2000.

11. Zhou H, Kepa JK, Siegel D, Miura S, Hiraki Y and Ross D: Benzene metabolite hydroquinone up-regulates chondromodulin-I and inhibits tube formation in human bone marrow endothelial cells. Mol Pharmacol 76: 579-587, 2009.

12. Tsai A-C, Pan S-L, Sun H-L, Wang CY, Peng CY, Wang SW, Chang YL, Kuo SC, Lee KH and Teng CM: CHM-1, a new vascular targeting agent, induces apoptosis of human umbilical vein endothelial cells via p53-mediated death receptor 5 up-regulation. J Biol Chem 285: 5497-5506, 2010.

13. Wang S-W, Pan S-L, Huang Y-C, Guh JH, Chiang PC, Huang DY, Kuo SC, Lee $\mathrm{KH}$ and Teng CM: CHM-1, a novel synthetic quinolone with potent and selective antimitotic antitumor activity against human hepatocellular carcinoma in vitro and in vivo. Mol Cancer Ther 7: 350-360, 2008.

14. Hsu SC, Yang JS, Kuo CL, Lo C, Lin JP, Hsia TC, Lin JJ, Lai KC, Kuo HM, Huang LJ, et al: Novel quinolone CHM-1 induces apoptosis and inhibits metastasis in a human osterogenic sarcoma cell line. J Orthop Res 27: 1637-1644, 2009.

15. Patra D and Sandell LJ: Antiangiogenic and anticancer molecules in cartilage. Expert Rev Mol Med 14: e10, 2012. 
16. Steck E, Bertram H, Abel R, Chen B, Winter A and Richter W: Induction of intervertebral disc-like cells from adult mesenchymal stem cells. Stem Cells 23: 403-411, 2005.

17. Pirker R, Pereira JR, von Pawel J, Krzakowski M, Ramlau R, Park K, de Marinis F, Eberhardt WE, Paz-Ares L, Störkel S, et al: EGFR expression as a predictor of survival for first-line chemotherapy plus cetuximab in patients with advanced nonsmall-cell lung cancer: Analysis of data from the phase 3 FLEX study. Lancet Oncol 13: 33-42, 2012.

18. Dalby B, Cates S, Harris A, Ohki EC, Tilkins ML, Price PJ and Ciccarone VC: Advanced transfection with Lipofectamine 2000 reagent: Primary neurons, siRNA, and high-throughput applications. Methods 33: 95-103, 2004.

19. Zhu C, Jung S, Luo S, Meng F, Zhu X, Park TG and Zhong Z: Co-delivery of siRNA and paclitaxel into cancer cells by biodegradable cationic micelles based on PDMAEMA-PCL-PDMAEMA triblock copolymers. Biomaterials 31: 2408-2416, 2010.

20. Ziyan W, Shuhua Y, Xiufang W and Xiaoyun L: MicroRNA-21 is involved in osteosarcoma cell invasion and migration. Med Oncol 28: 1469-1474, 2011.

21. Mera H, Kawashima H, Yoshizawa T, Ishibashi O, Ali MM, Hayami T, Kitahara H, Yamagiwa H, Kondo N, Ogose A, et al: Chondromodulin-1 directly suppresses growth of human cancer cells. BMC Cancer 9: 166, 2009.

22. Callow MG, Clairvoyant F, Zhu S, Schryver B, Whyte DB, Bischoff JR, Jallal B and Smeal T: Requirement for PAK4 in the anchorage-independent growth of human cancer cell lines. J Biol Chem 277: 550-558, 2002.

23. Schwartz MA and Assoian RK: Integrins and cell proliferation: Regulation of cyclin-dependent kinases via cytoplasmic signaling pathways. J Cell Sci 114: 2553-2560, 2001.

24. Schwartz MA and Ginsberg MH: Networks and crosstalk: Integrin signalling spreads. Nat Cell Biol 4: E65-E68, 2002.

25. Hayami T, Shukunami C, Mitsui K, Endo N, Tokunaga K, Kondo J, Takahashi HE and Hiraki Y: Specific loss of chondromodulin-I gene expression in chondrosarcoma and the suppression of tumor angiogenesis and growth by its recombinant protein in vivo. FEBS Lett 458: 436-440, 1999.

26. Sachdev SW, Dietz UH, Oshima Y, Lang MR, Knapik EW, Hiraki Y and Shukunami C: Sequence analysis of zebrafish chondromodulin-1 and expression profile in the notochord and chondrogenic regions during cartilage morphogenesis. Mech Dev 105: 157-162, 2001

27. Klinger P, Surmann-Schmitt C, Brem M, Swoboda B Distler JH, Carl HD, von der Mark K, Hennig FF and Gelse K: Chondromodulin 1 stabilizes the chondrocyte phenotype and inhibits endochondral ossification of porcine cartilage repair tissue. Arthritis Rheum 63: 2721-2731, 2011.

28. Chen K-F, Tai W-T, Chu P-Y, et al: STAT3 mediates regorafenibinduced apoptosis in hepatocellular carcinoma. Clin Cancer Res 20: 5768-5776, 2014.

29. Fujii M, Furumatsu T, Yokoyama Y, Kanazawa T, Kajiki Y, Abe $\mathrm{N}$ and Ozaki T: Chondromodulin-I derived from the inner meniscus prevents endothelial cell proliferation. J Orthop Res 31: $538-543,2013$
30. Shukunami C and Hiraki Y: Role of cartilage-derived antiangiogenic factor, chondromodulin-I, during endochondral bone formation. Osteoarthritis Cartilage 9 (Suppl A): S91-S101, 2001.

31. Fang W, Friis TE, Long X and Xiao Y: Expression of chondromodulin-1 in the temporomandibular joint condylar cartilage and disc. J Oral Pathol Med 39: 356-360, 2010.

32. Takeda K, Clausen BE, Kaisho T, Tsujimura T, Terada N, Förster I and Akira S: Enhanced Th1 activity and development of chronic enterocolitis in mice devoid of Stat 3 in macrophages and neutrophils. Immunity 10: 39-49, 1999.

33. Grivennikov S, Karin E, Terzic J, Mucida D, Yu GY, Vallabhapurapu S, Scheller J, Rose-John S, Cheroutre H, Eckmann L, et al: IL-6 and Stat3 are required for survival of intestinal epithelial cells and development of colitis-associated cancer. Cancer Cell 15: 103-113, 2009.

34. Corvinus FM, Orth C, Moriggl R, Tsareva SA, Wagner S, Pfitzner EB, Baus D, Kaufmann R, Huber LA, Zatloukal K, et al: Persistent STAT3 activation in colon cancer is associated with enhanced cell proliferation and tumor growth. Neoplasia 7: 545-555, 2005

35. Sherry MM, Reeves A, Wu JK and Cochran BH: STAT3 is required for proliferation and maintenance of multipotency in glioblastoma stem cells. Stem Cells 27: 2383-2392, 2009.

36. Gao Q, Wolfgang MJ, Neschen S, Morino K, Horvath TL, Shulman GI and Fu XY: Disruption of neural signal transducer and activator of transcription 3 causes obesity, diabetes, infertility, and thermal dysregulation. Proc Natl Acad Sci USA 101: 4661-4666, 2004.

37. Aggarwal BB, Sethi G, Ahn KS, Sandur SK, Pandey MK, Kunnumakkara AB, Sung B and Ichikawa H: Targeting signaltransducer-and-activator-of-transcription-3 for prevention and therapy of cancer: Modern target but ancient solution. Ann NY Acad Sci 1091: 151-169, 2006.

38. Blaskovich MA, Sun J, Cantor A, Turkson J, Jove R and Sebti SM: Discovery of JSI-124 (cucurbitacin I), a selective Janus kinase/ signal transducer and activator of transcription 3 signaling pathway inhibitor with potent antitumor activity against human and murine cancer cells in mice. Cancer Res 63: 1270-1279, 2003.

39. Chen T, Wang LH and Farrar WL: Interleukin 6 activates androgen receptor-mediated gene expression through a signal transducer and activator of transcription 3-dependent pathway in LNCaP prostate cancer cells. Cancer Res 60: 2132-2135, 2000.

40. Aggarwal BB, Kunnumakkara AB, Harikumar KB, Gupta SR, Tharakan ST, Koca C, Dey S and Sung B: Signal transducer and activator of transcription-3, inflammation, and cancer: How intimate is the relationship? Ann NY Acad Sci 1171: 59-76, 2009.

41. De Simone V, Franzè E, Ronchetti G, Colantoni A, Fantini MC, Di Fusco D, Sica GS, Sileri P, MacDonald TT, Pallone F, et al: Th17-type cytokines, IL- 6 and TNF- $\alpha$ synergistically activate STAT3 and NF- $\kappa \mathrm{B}$ to promote colorectal cancer cell growth. Oncogene: 2014 Sep 1, 2014 (Epub ahead of print). doi: 10.1038/ onc.2014.286. 